\title{
Parental strategies for assisting children to wait
}

\author{
Monica Cuskelly', Anne Jobling', Linda Gilmore² and Sheila Glenn ${ }^{3}$ \\ 'School of Education, The University of Queensland, Australia \\ ${ }^{2}$ School of Learning and Professional Studies, Faculty of Education, Queensland University of \\ Technology, Australia \\ ${ }^{3}$ Faculty of Health Sciences, John Moores University, Liverpool, UK.
}

\begin{abstract}
This study examined parents' behaviours as they waited with their child. Children were presented with an attractively wrapped gift and then asked not to touch it until the experimenter returned from finishing some work in another room. Three parent groups and their children participated in the study - parents of children with Down syndrome, parents of children with intellectual disability from another cause, and parents of children who were developing typically. There were no significant differences between children in how long they were able to wait before touching the gift. The data from the first two groups were combined for all analyses after it was established that there were no significant differences between them. There were few significant differences between parents of a child with intellectual disability and comparison parents. The former group were more likely to be classified as Authoritarian than were comparison parents, however with one exception, parenting style was unrelated to the strategies parents used in the waiting situation. Very few parents in either group used the opportunity to teach or explicitly praise effective waiting strategies in their children.
\end{abstract}

Keywords: Self-regulation, delay of gratification, parenting style, parent teaching, waiting

\section{Introduction}

Self-regulation is fundamental to the ways in which individuals manage their own learning and behaviour (Butler, 2002; Zimmerman, 2001). The development of the capacity for self-regulation represents an important achievement of childhood that is associated with social, behavioural and academic competence (Bronson, 2001). One defining aspect of self-regulation is the ability to delay gratification (Baumeister \& Heatherton, 1996). Delay of gratification occurs when an individual works towards the achievement of a distant goal and eschews more immediate but less desirable goals. In its most sophisticated form this process is entirely self-generated (known as self-imposed delay of gratification); however, there are many instances where individuals are required to delay gratification at someone else's behest (otherimposed delay of gratification).

Capacity to delay gratification, particularly self-imposed delay of gratification, has been shown to predict a range of intellectual and social outcomes for typically developing children (Shoda et al., 1990). Children who at age four were able to wait for a period of 15 minutes for a small reward had significantly better academic skills, embraced challenges and were more personally effective at adolescence than children who were able to wait for only a few moments. A later follow up study of these same children at 30 years of age showed continued positive advantages for those who could wait in early childhood (Ayduk et al., 2000).

The development of the capacity to delay gratification is influenced by both personal characteristics and by expe- 
rience. Chronological age (Houck \& LeCruyer-Maus, 2004; Mauro \& Harris, 2000), mental age (Cuskelly et al., 2003) and language ability (Cuskelly et al., 2001) have all been shown to be associated with ability to delay. Children with Down syndrome have been found to have difficulty delaying gratification in both other- and selfimposed situations (Cuskelly et al., 2003; Kopp, 1990) in comparison with mental age matched peers.

Maternal child-rearing approaches have been identified as important in the development of children's capacity to delay gratification (e.g., Olson et al., 1990; Vaughn et al., 1984). One categorisation of parenting approaches that has proven to be useful in understanding child development across a variety of outcomes was proposed by Baumrind (1971). Baumrind identified three approaches to parenting that differed around the dimensions of nurturance and restrictiveness. Authoritarian parents are those who are high on restrictiveness and low on nurturance; permissive parents are high on nurturance and low on restrictiveness; and authoritative parents are those who are high on nurturance and moderate on restrictiveness. Authoritative parenting has been found to be associated with better child outcomes than have the other two approaches in many studies, and across a range of outcomes (see Chao, 2001; Denham et al., 1991; Eccles et al., 1997, for example). Mauro and Harris (2000), Reitman and Gross (1997) and Silverman and Ragusa (1990) have all reported evidence that overcontrolling mothers and/or permissive mothers (based on Baumrind's classification) are less effective in developing self-regulation in their children than are authoritative mothers.

Parental styles manifest themselves in the ways parents interact with their children. For example, authoritarian parents are more likely to be directive and to use less explanation or reasoning with their child as they emphasise compliance (Schaefer, 1991). Diaz et al., (1992) suggested that the authoritative parenting style was most effective in developing self-regulation as it was likely to be associated with use of reasoning and verbal rationales, plus the gradual relinquishing of parental control which is necessary for children to fully develop self-regulation (Kopp, 1982).

Self-regulation, and therefore delay of gratification, requires the movement from dependence on others to dependence on oneself. Autonomy is clearly an important component of self-regulation as it is self - rather than other - regulated. Support for autonomy is defined as "the degree to which parents value and use techniques that encourage choice, self-initiation, and participation in making decisions" (Grolnick et al., 1997, p.148). At the other end of the continuum is the dimension of control that involves the use of controlling or restrictive techniques by parents who value obedience and compliance over autonomy (Grolnick et al., 1997). Grolnick and colleagues have provided evidence for the link between maternal support for autonomy and children's self-regulation (Grolnick \& Ryan, 1989: Grolnick et al., 1991).

While parenting style is likely to influence parental behaviour in waiting situations with their child, parental knowledge about strategies may also affect the way they behave in such situations. Work by Mischel and his colleagues has provided evidence about useful strategies in delay of gratification situations. They have found, for example, that distracting oneself (Mischel \& Baker, 1975; Peake et al., 2002), not looking at the reward (Mischel et al., 1972), and focusing on the 'cool' rather than the 'hot' properties all increase children's ability to wait (Mischel \& Baker, 1975). Cool properties are those that allow some abstraction while hot properties are those that draw attention to the desirability of the item. When waiting for marshmallows, for example, children who were told to think about them as fluffy clouds were able to wait longer than those who were instructed to think about how nice they would be to eat.

Hom and Knight (1996) found that mothers' knowledge of effective waiting strategies was poor. When asked, mothers endorsed the least effective strategies (as identified by Mischel and colleagues) as likely to be the most helpful in assisting their children to wait. When examining maternal strategies for teaching delay of gratification, Mauro and Harris (2000) found that mothers were more likely to focus on the task (i.e. don't touch!) than on strategies that might assist the child to wait. Regression analysis identified that mothers' focus on the demands of the task was the only significant predictor of their child's waiting time, accounting for $25 \%$ of the variance. The children of mothers who chose this strategy were less successful at waiting when left alone to wait.

Mothers whose children were not able to delay gratification both spoke much more frequently than did mothers whose children could delay and also spoke about the need to follow the rules significantly more often than mothers whose children did delay (Mauro \& Harris, 2000). In addition, children whose mothers suggested focusing on the gift had more difficulty waiting than those who mothers did not suggest this strategy. Restrictive child rearing attitudes were significantly associated with focusing on the task, with mothers with more restrictive attitudes suggesting this as a strategy to their child more frequently than mothers with other parenting orientations.

Houck and LeCuyer-Maus (2004) conducted a longitudinal study of maternal influences on children's capacities to delay gratification. Mothers' behaviour was observed at 12,24, and 36 months and then children were observed in a delay of gratification task at 5 years. Mothers who used an authoritarian, power-based style when interacting with their children had children who were less able to wait in a self-imposed delay of gratification task than children whose mothers used an authoritative approach. 
M. Cuskelly, A. Jobling, L. Gilmore and S. Glenn • Parental strategies for assisting children to wait

These latter mothers used firm control coupled with sensitive support, provided reasons and explanations and used developmentally appropriate distracting activities. These results reflected those of an earlier study in which LeCuyer-Maus and Houck (2002) found that children of mothers who employed a teaching style (clear limits, explanations, responsiveness and distractions) used more effective self-regulatory strategies in a delay of gratification task.

Parenting style has not been investigated in parents of children with Down syndrome, however there has been a lot of work on maternal directiveness. Mothers of children with Down syndrome have been shown in a number of studies to be more directive with their children (e.g., Cardoso-Martins \& Mervis, 1985; Mahoney \& Robenalt, 1986; Tannock, 1988). This behaviour is what one might expect from parents who endorse an authoritarian parenting style. Authoritarian parenting, if it is practised regularly by parents in their interactions with their children, is likely to inhibit the development of selfregulatory behaviours. It is also possible, of course, that the parents of children with Down syndrome may be directive, not because of an inherently different parenting style, but in response to the perceived needs of their child (Mahoney et al., 1990; Marfo, 1990).

The aim of this study was to investigate the strategies that mothers of children with intellectual disability use to assist their child to wait and to compare these strategies with those employed by mothers of typically developing children matched for mental age.

\section{Method}

\section{Participants}

Twenty-one children with Down syndrome, 18 children with intellectual disability from other causes, and 43 children who were developing typically were included in the study. Table 1 contains the demographic information on participants. There was a significant difference on children's chronological age. Post hoc analysis (Tukey's HSD) showed that typically developing children were significantly younger ( $\mathrm{M}=3 \mathrm{yrs} 10 \mathrm{mths})$ than the other two groups and that the children with intellectual disability ( $\mathrm{M}=10 \mathrm{yrs} 7 \mathrm{mths}$ ) were significantly younger than the children with Down syndrome $(\mathrm{M}=12 \mathrm{yrs} 0 \mathrm{mths})$. There was no significant difference when the chronological age of children developing typically was compared with the mental ages of the other groups. When parental variables were compared, significant differences were found only for parental age and education. Fathers of typically developing children were younger than fathers of both other groups and there was no significant difference in the ages of fathers of children with Down syndrome or children with intellectual disability from other causes. Mothers of the children with Down syndrome were significantly older than the other groups of mothers. There was no difference in maternal age between mothers of children with intellectual disability and mothers of children who were developing typically. Education was classified on a 5 point scale: completed primary school, completed secondary school; completed trade qualification; completed undergraduate degree; completed postgraduate degree. Chi square analysis showed significant differences between both mothers and fathers of children who were typically developing and the children with intellectual disability (both $p<.01$ ). Mothers and fathers of typically developing children were better educated than both groups of parents of children with intellectual disability, and there were no significant differences between parents of children with Down syndrome and parents of children with intellectual disability on education.

\section{Measures}

The Stanford-Binet Intelligence Scale, $4^{\text {th }}$ Edition (SB: IV; Thorndike, et al., 1986) is a psychometrically sound instrument and was used to provide a measure of Mental Age (MA) for the children with intellectual disability. It is suitable for children across the age range in this study.

\begin{tabular}{|l|c|c|c|c|}
\hline & $\begin{array}{c}\text { Typically developing } \\
\text { children } \\
\mathbf{n}=\mathbf{4 3}\end{array}$ & $\begin{array}{c}\text { Children with } \\
\text { Down syndrome } \\
\mathbf{n = 2 1}\end{array}$ & $\begin{array}{c}\text { Children with } \\
\text { intellectual disability } \\
\mathbf{n}=18\end{array}$ & $\begin{array}{c}\boldsymbol{F} \\
\mathbf{d f}(\mathbf{2 , 7 9 )}\end{array}$ \\
\hline Chronological age (months) & $45.81(5.69)$ & $144.1(19.86)$ & $127.39(26.09)$ & $323.44^{* *}$ \\
\hline SB IV AE (months) & & $47.19(7.12)$ & $49.33(8.03)$ & \\
\hline PPVT-III AE (months) & $50.26(15.16)$ & $48.90(15.30)$ & $54.44(16.86)$ & 0.67 \\
\hline EVT AE (months) & $51.86(12.93)$ & $49.43(7.96)$ & $45.28(17.01)$ & 1.66 \\
\hline Maternal age (years) & $35.95(4.78)$ & $44.86(4.86)$ & $38.61(5.86)$ & $21.93^{* *}$ \\
\hline Paternal age (years) & $38.16(6.71)$ & $46.11(6.03)^{\mathrm{a}}$ & $41.81(7.25)^{\mathrm{b}}$ & $9.56^{* *}$ \\
\hline
\end{tabular}

\section{Table 1. Means (standard deviations) of the demographic characteristics of children and families}


The Peabody Picture Vocabulary Test-III (PPVT-III; Dunn \& Dunn, 1997) assesses receptive vocabulary across the age range 2.5 to 90 years.

The Expressive Vocabulary Test (EVT; Williams, 1997) assesses expressive vocabulary and word retrieval in those between 2.5 to 90 years. Both language instruments have good reliability and validity and have been used successfully with individuals with intellectual disability. Both provide age equivalent scores and these were used in the current study.

The Child Rearing Practices Report (CRPR) (adapted by Rickel \& Biasatti, 1982) is a maternal report that provides information about two aspects of parenting: nurturance and restrictiveness. These two aspects can be used to identify parents' typical parenting style (Dekovic et al., 1991).

The Gift Task is based on the externally-imposed delay task used by Block and Block (1980). The experimenter shows the child a brightly wrapped gift, tells the child the gift is for him/her, and explains that the experimenter has to leave the room for a few minutes. The experimenter tells the child not to touch the gift until s/he returns. The experimenter returns after 15 minutes, whether or not the child complies with the instruction.

\section{Procedure}

Children with intellectual disability were assessed with the SB:IV, the PPVT-III and the EVT before the experimental session. The assessments were generally carried out at the child's school, but some families chose to have the assessment at the university. Comparison children completed the PPVT-III and the EVT at the university after the experimental session. Prior to the experimental session beginning, parents were told that the session was to assist understanding what helps children to wait, and to do as they would usually do in such a situation. Delay time was recorded as the latency between the instruction and the first occasion when the child touched the gift. The number of times the child touched the gift was also recorded. The session was videotaped to allow later coding of parental behaviours. Parent behaviours were coded as one of the following: distracting the child from the task (parent initiated); reminding the child about the rules; giving the child a choice about his/her behaviour with respect to the rules; praising the child for his/her waiting; physically enforcing the rules (e.g., removing the box from the child's reach); giving verbal direction to the child to comply with the rules; reassuring the child about the researcher's return; interacting with the child on a child initiated activity; focusing on the target (e.g., "I wonder what is inside the box"); teaching the child strategies to wait; and passive regard. Definitions are available from the first author on request. Each 15 second period was coded. All dyads were recorded for a full 15 minute period, irrespective of whether the child touched or opened the gift. Parents completed the questionnaire after the experimental session was over.

Children with autism and Prader-Willi syndrome were excluded from the study.

\section{Results}

Preliminary analyses revealed that mothers' age was unrelated to strategy use and therefore this variable was ignored in all subsequent analyses. A one-way ANOVA was conducted with time to first touch as the dependent variable and group (typically developing, Down syndrome, intellectual disability from other cause) as the independent variable. No difference in waiting time was observed, $F(2,79)=.60 p=$ ns. Preliminary analyses of maternal strategies revealed few differences between the behaviours of mothers of children with Down syndrome and those who had a child with intellectual disability from other causes and so the data from these two groups were combined for all further analyses. This combined group is referred to as children with intellectual disability.

\section{Parental strategies}

Table 2 contains details about the proportion of time mothers employed the various strategies described above during the waiting task. As most parental strategies were not normally distributed, Mann Whitney U was used to examine differences between groups. $P$ was set at .01 to reduce the likelihood of Type 1 error. In comparison to parents of typically developing children, parents of children with intellectual disability engaged in significantly fewer occasions of giving the child a choice about his/her behaviour with respect to the rules, reassuring the child about the researcher's return, and focusing on the target. There was a trend for parents of children with intellectual disability to remind their children about the rules less frequently than parents of children who were developing typically $(\mathrm{U}=609.5 ; p=.03)$. A number of these behaviours were demonstrated very infrequently so the meaning of these differences is unclear. Eighty-four percent of all parents never gave their child a choice about their behaviour, $72 \%$ never praised their child for waiting, 78\% never physically enforced the rules and $88 \%$ never used the opportunity to teach their child about strategies to use while waiting.

A Principal components factor analysis with varimax rotation was used to establish if there was an interpretable underlying structure to parental behaviours in this task. The four behaviours which the vast majority of parents never used, described above, were excluded from this analysis. The factor analysis revealed four clear factors with an eigenvalue $>1$ which accounted for $76 \%$ of 
M. Cuskelly, A. Jobling, L. Gilmore and S. Glenn • Parental strategies for assisting children to wait

the variance. The four factors were labelled Parent Direction, Child Direction, Rules Focus, and Target Focus. See Table 3.

A Mann Whitney $U$ test revealed a significant difference between parent groups on the Target Focus factor $(\mathrm{U}=405.5, p<$ $.001)$ with parents of typically developing children having a greater focus on the target than parents of children with intellectual disability, i.e., they commented about, pointed to, touched etc. the gift more frequently (Mean rank = $51.57 ; 30.40$, respectively). There was a trend towards a significant difference for Factor 3 - Rules Focus (U $=626.5, p=.048)$. Comparison parents were more likely to focus on the rules while waiting than were the parents of children with intellectual disability (Mean rank $=46.43 ; 36.06$, respectively).

Repeated measures analysis revealed that parental use of the behaviours contributing to the four factors differed significantly. Follow up testing revealed that all factors differed significantly from all others (M Parent Directed $=65.78$ (14.38), Child Directed $=23.11$ (10.18), Rules Focus $=4.46$ (3.99), Target Focus $=9.69(6.58)$ ). The vast majority of the time was spent by parents distracting

${ }^{*} p<.05{ }^{* *} p<.01{ }^{* * *} p<.001$ used by mothers

\begin{tabular}{|c|c|c|c|}
\hline Maternal strategy & $\begin{array}{c}\text { Typically } \\
\text { developing children } \\
n=43\end{array}$ & $\begin{array}{c}\text { Children with } \\
\text { intellectual disability } \\
n=39\end{array}$ & Mann Whitney U \\
\hline $\begin{array}{l}\text { Distracting child from the } \\
\text { task (parent initiated) }\end{array}$ & $\begin{array}{c}20.80(14.84) \\
{[41.80]}\end{array}$ & $\begin{array}{c}20.09(14.63) \\
{[41.17]}\end{array}$ & ns \\
\hline $\begin{array}{l}\text { Reminding child about the } \\
\text { rules }\end{array}$ & $\begin{array}{c}3.45(2.58) \\
{[46.83]}\end{array}$ & $\begin{array}{c}2.44(2.96) \\
{[35.63]}\end{array}$ & $609.5^{*}$ \\
\hline $\begin{array}{l}\text { Giving child a choice about } \\
\text { his/her behaviour }\end{array}$ & $\begin{array}{c}0.62(1.31) \\
{[45.56]}\end{array}$ & $\begin{array}{l}0.08(0.37) \\
{[37.03]}\end{array}$ & $664.0 * *$ \\
\hline Praising child for waiting; & $\begin{array}{c}0.58(1.02) \\
{[42.40]}\end{array}$ & $\begin{array}{c}0.73(1.83) \\
{[40.73]}\end{array}$ & ns \\
\hline Physically enforcing the rules & $\begin{array}{c}0.97(3.11) \\
{[38.12\}}\end{array}$ & $\begin{array}{c}4.62(13.43) \\
{[45.23]}\end{array}$ & ns \\
\hline $\begin{array}{l}\text { Giving verbal direction to } \\
\text { child to comply with the } \\
\text { rules }\end{array}$ & $\begin{array}{l}4.54(4.12) \\
{[44.17]}\end{array}$ & $\begin{array}{c}4.40(6.47) \\
{[38.55]}\end{array}$ & ns \\
\hline $\begin{array}{l}\text { Reassuring child about the } \\
\text { researcher's return }\end{array}$ & $\begin{array}{c}2.52(2.53) \\
{[49.34]}\end{array}$ & $\begin{array}{c}0.98(1.70) \\
{[32.86]}\end{array}$ & $501.5^{* *}$ \\
\hline $\begin{array}{l}\text { Interacting with child on a } \\
\text { child initiated activity }\end{array}$ & $\begin{array}{c}37.67(14.00) \\
{[41.91]}\end{array}$ & $\begin{array}{c}39.44(19.87) \\
{[41.05]}\end{array}$ & ns \\
\hline Focusing on the target & $\begin{array}{c}17.27(8.60) \\
{[50.34]}\end{array}$ & $\begin{array}{l}11.11(11.10) \\
{[31.76]}\end{array}$ & $458.5^{* * *}$ \\
\hline Teach a waiting strategy & $\begin{array}{c}0.47(1.43) \\
{[43.09]}\end{array}$ & $\begin{array}{c}0.26(0.98) \\
{[39.74]}\end{array}$ & ns \\
\hline Passive regard & $\begin{array}{c}8.37(9.63) \\
{[39.51]}\end{array}$ & $\begin{array}{c}13.55(9.63) \\
{[43.68]}\end{array}$ & ns \\
\hline
\end{tabular}

Table 2. Mean percentage (SD) and [mean rank] of occasions when a strategy was

their child, followed by the parent responding to child initiated distraction. Focusing on the target was used by parents more frequently than was reminding the child of the rules.

Spearman correlations were used to examine associations between time to first touch, number of touches, chronological age, cognitive functioning (MA) language functioning (PPVT-III; EVT), and parental age and education with the factors developed from parental strategies

\begin{tabular}{|l|c|c|c|c|c|}
\hline & Parent Direction & Child Direction & Rules Focus & Target Focus & Communality \\
\hline $\begin{array}{l}\text { Distracting child from the } \\
\text { task (parent initiated) }\end{array}$ & .791 & .327 & -.009 & -.350 & .864 \\
\hline $\begin{array}{l}\text { Reminding child about the } \\
\text { rules }\end{array}$ & .170 & -.005 & .721 & .123 & .567 \\
\hline $\begin{array}{l}\text { Giving verbal direction to } \\
\text { child to comply with the } \\
\text { rules }\end{array}$ & -.008 & .139 & .846 & -.005 & .744 \\
\hline $\begin{array}{l}\text { Reassuring child about the } \\
\text { researcher's return }\end{array}$ & -.004 & -.142 & .109 & .748 & .594 \\
\hline $\begin{array}{l}\text { Interacting with child on a } \\
\text { child initiated activity }\end{array}$ & .001 & -.953 & -.107 & -.002 & .920 \\
\hline Focusing on the target & .006 & .470 & -.008 & .738 & .778 \\
\hline Passive regard & -.840 & .250 & -.205 & -.244 & .862 \\
\hline
\end{tabular}

Table 3. Factor structure of parental behaviour during waiting task 
during the waiting task. Very few significant associations emerged and all are reported below. None of the factors was associated with time to first touch for either group, however, for both groups parents' use of strategies that focused on the rules was positively correlated with the number of times their child touched the gift $(r h o=.45$, $p<.01$; rho $=.56, p<.001$ for typically developing children and those with intellectual disability, respectively). For the comparison group, children's chronological age was negatively correlated with strategies that focused on parental direction $(r h o=-.44, p<.01)$, and this factor was also negatively correlated with the Child Direction factor $(r h o=-.38, p<.01)$. Parents who took control by distracting their child were unlikely to follow their child's lead during the waiting session. Only one association reached significance for the groups with a child with intellectual disability. Chronological age was negatively correlated with parents taking a rules focus $(r h o=-.41, p<.01)$.

\section{Parenting style}

Parents were divided into Authoritative, Permissive or Authoritarian parenting style on the basis of their score on the Restrictiveness subscale of the CRPR. Parents whose score on this subscale fell between + one and - one standard deviation from the mean were classified as Authoritative $(n=53)$, those who were more than one standard deviation below the mean were classified as Permissive $(n=13)$ and those who were more than one standard deviation above the mean were classified as Authoritarian $(\mathrm{n}=16)$. In addition to being significantly different on the Restrictiveness scale, chi $^{2}=58.29$ (2) $p$ $<.001$, (mean rank: Authoritative, 40.00; Permissive, 7.00; Authoritarian, 74.50) there was also a significant difference on the Nurturance scale, chi $^{2}=6.86$ (2) $p<$ .05 (mean rank: Authoritative, 38.25; Permissive, 57.31; Authoritarian, 39.44) with Permissive parents reporting higher levels of nurturance than either Authoritative or Authoritarian parents. There was no significant correlation between scores on the Restrictiveness and Nurturance measures for either group of parents.

Chi square revealed significant differences between parents of children with intellectual disability and the comparison group on parenting style, $\mathrm{chi}^{2}=6.18(2), p<.05$ (see Table 4). Parents of children with intellectual disability were less authoritative in their parenting style and

\begin{tabular}{|l|c|c|}
\hline Parenting style & $\begin{array}{c}\text { Parents of typically } \\
\text { developing children }\end{array}$ & $\begin{array}{c}\text { Parents of children with } \\
\text { intellectual disability }\end{array}$ \\
\hline Authoritative & $74 \%$ & $54 \%$ \\
\hline Permissive & $16 \%$ & $15 \%$ \\
\hline Authoritarian & $9 \%$ & $31 \%$ \\
\hline
\end{tabular}

Table 4. Proportions of Authoritative, Permissive and Authoritarian parents by group more authoritarian than parents of children who were developing typically. Parenting style was unrelated to scores on the parental strategy factors for both groups. In order to ensure that we were not overlooking important data we examined the effect of parenting style on the four parental strategies that were not included in the factor analysis using Kruskal Wallis. Physically enforcing the rules was the only behaviour to reach significance $\mathrm{chi}^{2}=$ $7.12(2), p<.05$. Follow up testing revealed the difference lay between Authoritative and Authoritarian parents ( $U$ $=287.5, p<.01$ ) with the latter engaging in this behaviour more frequently (mean rank Authoritative $=32.42$; Authoritarian $=43.53)$.

\section{Discussion}

Factor analysis of parental behaviour during the other imposed waiting task revealed four factors that accounted for a large proportion of the variance $(76 \%)$. These factors included one labelled Parent Direction and parents who scored highly on this factor spent a lot of their time taking responsibility for filling the waiting time by distracting their child. The second factor, labelled Child Direction, related to parental behaviour that was in response to their child's initiations. For parents of children who were developing typically, these two factors were negatively correlated. The third factor, Rules Focus, comprised two behaviours, reminding the child of the rules and verbally requiring the child to comply with the rules. These had been conceptualised as distinct on the assumption that the first was providing the child with responsibility, however, it would appear that, in practice, these two behaviours are very similar. The fourth factor was labelled Target Focus and reflected parental behaviour that ensured the child's attention was on the gift.

Parents of typically developing children brought their child's attention to the gift more frequently than did the parents of children with intellectual disability. Focusing on the target was identified by Mischel (Mischel et al., 1972) as a poor strategy in delay of gratification situations as it increases the frustration associated with the waiting. In this study, however, there was no association between the amount of time parents focused on the gift and the time to first touch. Mischel's work was related to children waiting for a reward in a situation where the decision to wait was self-imposed. While the capacity to wait in other imposed situations has been suggested to be an important precursor to waiting in self-imposed waiting situations it is possible that the strategies that are effective in one are not those that are effective in the other. Other-imposed waiting is a situation from which there is no escape and Karniol and Miller (1991) found that, in these circumstances, thinking about the incentive reduced 
M. Cuskelly, A. Jobling, L. Gilmore and S. Glenn • Parental strategies for assisting children to wait

frustration. In fact, anticipation in such a circumstances can be pleasurable, rather than frustrating. Parents may be operating on the belief that children will find waiting less tedious if they are focused on the excitement of the surprise gift. The usefulness of this strategy in teaching children skills for delaying gratification in self-imposed tasks is a question that remains to be answered.

There was a trend for the comparison group to verbally reinforce the rules more often than parents of a child with intellectual disability. For both groups, a focus on the rules was moderately positively correlated with the number of times children touched the box. While causality cannot be established by correlation, it seems very likely that parental behaviour was in response to the children's behaviour. As children touched the box, parents reminded them of the rules in order to increase compliance with the researcher's instruction.

For the typically developing group, parents were less likely to use parent directed distraction with older children. This suggests that children were becoming less dependent on external support while waiting, however, there was no commensurate relationship between age and parents following their child's lead while waiting for the time to pass. For children with intellectual disability, chronological age was negatively correlated with parents verbally reminding them of the rules. Parental strategy use was unrelated to mental age in this group.

The data used in the factor analysis did not contain all the observational data that was collected. Some behaviours occurred very seldom and so were not included when the factors were being developed. Behaviours that were excluded were giving the child a choice about waiting, praising the child for waiting, physically enforcing waiting, and teaching the child strategies for waiting. With the exception of physically enforcing waiting, these behaviours are those we would expect to see in parents who were taking a pro-active approach to developing self-regulation in their child. In particular, the fact that parents did not use this opportunity to either teach strategies to use in waiting situations, or praise effective waiting, undermines the assumption that external influences in waiting in other imposed situations are central to the development of the capacity to delay gratification in selfimposed situations.

Parents of children with intellectual disability were found to be more authoritarian and less authoritative in their parenting than parents of children who were developing typically. This reflects the literature that has identified this group as being more directive in their parenting than parents of children without a disability. Physical enforcement was found to differ significantly between authoritarian parents and authoritative parents, with authoritarian parents engaging in significantly more of this behaviour. Parenting style was unrelated, however, to the factors created from the factor analysis. This was unexpected. In particular, it might be anticipated that authoritarian parents would be more rules focused than other parents as found by Mauro and Harris (2000). The way in which parents were classified ensured that the majority would be considered to be Authoritative, however the resulting small numbers classified as Permissive or Authoritarian may have reduced the associations with parental behaviour.

There are clearly limitations associated with collecting data in an experimental setting. The impact on parental (and perhaps child) behaviour is unable to be ascertained, but could be substantial. In addition, the effect of the experimental setting may be more profound on the behaviour of one group than another. Naturalistic observations of parental behaviour in other imposed waiting situations may provide more useful understandings of how parents behave in such situations, if they are able to be gathered.

Finally, this paper reports on research in progress. More data will be collected from families of children with Down syndrome and those who have a child with intellectual disability from other causes. This will increase the power of the comparison between these two groups. It is possible that larger groups will reveal some differences between these two groups that are not apparent with such small samples.

\section{Correspondence}

Monica Cuskelly • School of Education, The University of Queensland, Q4072, Australia •E-mail: m.cuskelly@uq. edu.au

\section{References}

Ayduk. O., Mendoza-Denton, R., Mischel, W., Downey, G., Peake, P. \& Rodriguez, M. (2000). Regulating the interpersonal self: Strategic self-regulation for coping with rejection sensitivity. Journal of Personality and Social Psychology, 79, 776-792.

Bandura, A. (1997). Self-efficacy: The Exercise of Control. New York: W.H. Freeman \& Co.

Baumeister, R.F. \& Heatherton, T.F. (1996). Self-regulation failure: an overview. Psychological Inquiry, 7, 1-15.

Baumrind, D. (1971). Current patterns of parental authority. Developmental Psychology, 4(1, Pt2), 1-103.

Block, J.H. \& Block, J. (1980). The role of ego-control and ego-resiliency in the organization of behavior. In W.A. Collins (Ed.), Minnesota Symposium on Child Psychology (pp.53-107). Hillsdale, NJ: Erlbaum.

Bronson, M.B. (2001). Self-regulation in Early Childhood: Nature and Nurture. New York: Guilford Press. 
Butler, D.L. (2002). Qualitative approaches to investigating self-regulated learning: Contributions and challenges. Educational Psychologist, 37, 59-63.

Cardoso-Martins, C. \& Mervis, C.B. (1985). Maternal speech to prelinguistic children with Down syndrome. American Journal of Mental Deficiency, 89, 451-458.

Chao, R.K. (2001). Extending research on the consequences of parenting style for Chinese Americans and European Americans. Child Development, 72, 1832-1843.

Cuskelly, M., Einam, M. \& Jobling, A. (2001). Delay of gratification in young adults with Down syndrome. Down Syndrome Research and Practice, 7(2), 60-67.

Cuskelly, M., Zhang, A. \& Hayes, A. (2003). A mental age matched comparison study of delay of gratification in children with Down syndrome. International Journal of Disability, Development and Education, 50, 239-251.

Dekovic, M., Janssens, J.M.A.M. \& Gerrism J.M.R. (1991). Factor structure and construct validity of the Block Child Rearing Practices Report (CRPR). Psychological assessment: A Journal of Consulting and Clinical Psychology, 3, 182-187.

Denham, S.A., Renwick, S.M. \& Holt, R.W. (1991). Working and playing together. Prediction of preschool social-emotional competence from motherchild interaction. Child Development, 62, 242-249.

Diaz, R.M. Neal, C.J. \& Amaya-Wiliams, M. (1992). The social origins of self-regulation. In L.E. Moll (Ed.). Vygotsky and Education: Instructional Implication and Applications of Sociohistorical Society (pp. 127-154). Cambridge: Cambridge University Press.

Dunn, L.M. \& Dunn, L.M. (1997). Peabody Picture Vocabulary Test - Third Edition. Circle Pines, MN: American Guidance Service.

Eccles, J.S., Early, D., Frasier, K., Belansky, E. \& McCarthy, K. (1997). The relation of connection, regulation, and support for autonomy to adolescents' functioning. Journal of Adolescent Research, 12, 263-286.

Grolnick, W.S., Deci, E.L. \& Ryan, R.M. (1997). Internalization within the family: The self-determination theory perspective. In J.E. Grusec \& L. Kuczynski (Eds.). Parenting and Children's Internalization of Values: A Handbook of Contemporary Theory (pp. 135161). New York: Wiley.

Grolnick, W.S. \& Ryan, R.M. (1989). Parent styles associated with children's self-regulation and competence in school. Journal of Educational Psychology, 81,143154.

Grolnick, W.S., Ryan, R.M. \& Deci, E.L. (1991). The inner resources for school achievement: Motivational mediators of children's perceptions of their parents. Journal of Educational Psychology, 83, 508-517.

Hom, H.L. \& Knight, H. (1996). Delay of gratification: Mothers' predictions about four attentional techniques. Journal of Genetic Psychology, 157, 180-191.

Houck, G.M. \& LeCuyer-Maus, E.A. (2004). Maternal limit setting during toddlerhood, delay of gratification, and behavior problems at age five. Infant Mental Health Journal, 25, 28-46.

Karniol, R. \& Miller, D.T. (1991). The development of self-control in children. In S.S. Brehm, S.M. Kassin \& F.X. Gibbons (Eds.). Developmental Social Psychology, (pp.32-50). Oxford: Oxford University Press.

Kopp, C.B. (1982). The antecedents of self-regulation. Developmental Psychology, 18, 199-214.

Kopp, C.B. (1990). The growth of self-monitoring among young children with Down syndrome. In D. Cicchetti \& M. Beeghly (Eds.). Children with Down Syndrome: A Developmental Perspective (pp. 231-251). Cambridge: Cambridge University Press.

LeCuyer-Maus, E.A. \& Houck, G.M. (2002). Mothertoddler interaction and the development of self-regulation in a limit setting context. Journal of Pediatric Nursing, 17, 184-200.

Mahoney, G., Fors, S. \& Wood, S. (1990). Maternal directive behavior revisited. American Journal on Mental Retardation, 94, 398-406.

Mahoney, G. \& Robenalt, K. (1986). A comparison of conversational patterns between mothers and their Down syndrome and normal infants. Journal of the Division for Early Childhood, 10, 172-180.

Marfo, K. (1990). Maternal directiveness in interactions with mentally handicapped children: An analytical commentary. Journal of Child Psychology and Psychiatry and Allies Disciplines, 31, 531-549.

Mauro, C.F. \& Harris, Y.R. (2000). The influence of maternal child-rearing attitudes and teaching behaviours on preschoolers' delay of gratification. Journal of Genetic Psychology, 161, 293-308.

Mischel, W. \& Baker, N. (1975). Cognitive appraisal and transformations in delay behavior. Journal of Personality and Social Psychology, 31, 254-261.

Mischel, W., Ebbesen, E.B. \& Zeiss, A.R. (1972). Cognitive and attentional mechanisms in delay of gratification. Journal of Personality and Social Psychology, 21, 204-218.

Olson, S.L., Bates, J.E. \& Bayles, K. (1990). Early antecedents of childhood impulsivity: The role of parent-child interaction, cognitive competence, and temperament. Journal of Abnormal Child Psychology, $18,317-334$.

Peake, P.K., Hebi, M. \& Mischel, W. (2002). Strategic attention deployment for delay of gratification in 
working and waiting situations. Developmental Psychology, 38, 313-326.

Reitman, D. \& Gross, A.M. (1997). The relation of maternal child-rearing attitudes to delay of gratification among boys. Child Study Journal, 27, 279-302.

Rickel, A.U. \& Biasatti, L.L. (1982). Modification of the Block Child Rearing Practices Report. Journal of Clinical Psychology, 38, 129-334.

Schaefer, E.S. (1991). Goals for parent and future-parent education: Research on parental beliefs and behaviour. The Elementary School Journal, 91, 239-247.

Shoda, Y., Mischel, W. \& Peake, P.K. (1990). Predicting adolescent cognitive and self-regulatory competencies from preschool delay of gratification. Developmental Psychology, 26, 9768-986.

Silverman, I.W. \& Ragusa, D.M. (1990). Child and maternal correlates of impulse control in 24-monthold children. Genetic, Social, and General Psychology Monographs, 116, 437-474.

Tannock, R. (1988). Mothers' directiveness in their interactions with their children with and without Down syndrome. American Journal on Mental Retardation, 93, 154-165.

Thorndike, R.L., Hagan, E.P. \& Sattler, J.M. (1986). The Stanford-Binet Intelligence Scale: Fourth Edition. Chicago: Riverside Publishing.

Vaughn, B.E., Kopp, C.B. \& Krakow, J.B. (1984). The emergence and consolidation of self-control from eighteen to thirty months of age: Normative trends and individual differences. Child Development, 55, 990-1004.

Williams, K.T. (1997). Expressive Vocabulary Test. Circle Pines, MN: American Guidance Service.

Zimmerman, B.J. (2001). Theories of self-regulated learning and academic achievement: An overview and analysis. In B.J. Zimmerman \& D.H. Shunk, (Eds.). Self-regulated learning and academic achievement: Theoretical perspectives (pp. 1-37). Mahway, NJ: Lawrence Erlbaum. 